\title{
Batch-Mode Clinical-Scale Optical Hyperpolarization of Xenon-129 Using an Aluminum Jacket with Rapid Temperature Ramping
}

\author{
Jonathan R. Birchall, Panayiotis Nikolaou,* Aaron M. Coffey, Bryce E. Kidd, Megan Murphy, \\ Michael Molway, Liana B. Bales, Boyd M. Goodson, Robert K. Irwin, Michael J. Barlow, \\ and Eduard Y. Chekmenev*
}

Cite This: https://dx.doi.org/10.1021/acs.analchem.9b05051

Read Online

ACCESS | Lill Metrics \& More | 回 Article Recommendations | st Supporting Information

ABSTRACT: We present spin-exchange optical pumping (SEOP) using a third-generation (GEN-3) automated batch-mode clinicalscale ${ }^{129} \mathrm{Xe}$ hyperpolarizer utilizing continuous high-power $(\sim 170$ W) pump laser irradiation and a novel aluminum jacket design for rapid temperature ramping of xenon-rich gas mixtures (up to $2 \mathrm{~atm}$ partial pressure). The aluminum jacket design is capable of heating SEOP cells from ambient temperature (typically $25{ }^{\circ} \mathrm{C}$ ) to $70{ }^{\circ} \mathrm{C}$ (temperature of the SEOP process) in $4 \mathrm{~min}$, and perform cooling

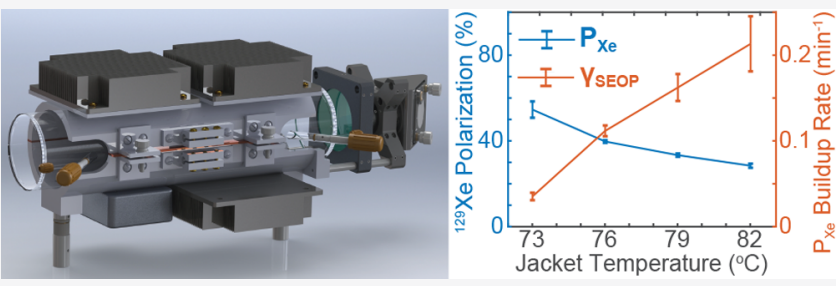
of the cell to the temperature at which the hyperpolarized gas mixture can be released from the hyperpolarizer (with negligible amounts of $\mathrm{Rb}$ metal leaving the cell) in approximately $4 \mathrm{~min}$, substantially faster (by a factor of 6 ) than previous hyperpolarizer designs relying on air heat exchange. These reductions in temperature cycling time will likely be highly advantageous for the overall increase of production rates of batch-mode (i.e., stopped-flow) ${ }^{129} \mathrm{Xe}$ hyperpolarizers, which is particularly beneficial for clinical applications. The additional advantage of the presented design is significantly improved thermal management of the SEOP cell. Accompanying the heating jacket design and performance, we also evaluate the repeatability of SEOP experiments conducted using this new architecture, and present typically achievable hyperpolarization levels exceeding $40 \%$ at exponential build-up rates on the order of $0.1 \mathrm{~min}^{-1}$.

$\mathrm{H}$ yperpolarized noble gases such as ${ }^{3} \mathrm{He},{ }^{83} \mathrm{Kr}$, and ${ }^{129} \mathrm{Xe}$ have seen use in a multitude of NMR and magnetic resonance imaging (MRI) applications, including spectroscopic biosensing, spectroscopic studies of porous media, theranostic imaging of the lungs and brain, and others. ${ }^{1-25}$ NMR signal is directly proportional to the degree of nuclear spin alignment with the applied static magnetic field or nuclear spin polarization, $P$. The low $P$ of such isotopes possessing nonzero spin intrinsically limits the achievable signal-to-noise ratio (SNR) for use in spectroscopic or imaging applications. It is therefore necessary to increase the net nuclear spin polarization of these systems to several orders of magnitude above those found at thermal equilibrium, ${ }^{23,26,27}$ with nearunity polarization becoming more accessible with recent advancements in hyperpolarizer design. ${ }^{28}$

Circularly polarized photons can be employed for electron spin hyperpolarization of a vaporized alkali metal (such as rubidium). Hyperpolarization of ${ }^{129} \mathrm{Xe}$ is usually achieved by transferring angular momentum from the hyperpolarized (HP) electron of the vaporized alkali metal via Fermi contact interactions. ${ }^{29-31}$ This two-stage spin-exchange optical pumping (SEOP) process creates a population excess in a particular ${ }^{129} \mathrm{Xe}$ spin state, significantly increasing the net ${ }^{129} \mathrm{Xe}$ polarization and hence NMR signal intensity. Production of HP ${ }^{129} \mathrm{Xe}$ contrast agent typically occurs in either a batch- mode (stopped-flow) or continuous flow modality, both of which present substantial differences in ${ }^{129} \mathrm{Xe} P$ build-up and energy transport dynamics. ${ }^{32-38}$

In addition to ${ }^{129} \mathrm{Xe}$ target nuclei, molecular nitrogen $\left(\mathrm{N}_{2}\right)$ is typically included in the gas mixture to quench radiative, randomly polarized emission (fluorescence) from excited $\mathrm{Rb}$ atoms via gas-phase collisions, thus mitigating what would otherwise be a major source of electron spin-relaxation. ${ }^{32,39}$ Helium-4 has also seen some use as a buffer gas, particularly in continuous-flow polarizer designs, ${ }^{32,40,41}$ to perform pressure broadening of the $\mathrm{Rb}$ absorption lines $\left(\mathrm{D}_{1} \sim 795 \mathrm{~nm}, \mathrm{D}_{2} \sim 780\right.$ $\mathrm{nm})^{42-44}$ and thus increase the optical pumping efficiency. The advent of frequency-narrowed, high-power laser diode arrays (LDAs) ${ }^{28,45-49}$ has made the inclusion of ${ }^{4} \mathrm{He}$ less critical in batch-mode hyperpolarizer designs. Despite these advances, the significant increases in thermal conductivity and specific heat capacity afforded by He-rich ternary gas mixtures relative to their binary $\mathrm{Xe} / \mathrm{N}_{2}$ counterparts may make them

Received: November 6, 2019

Accepted: February 19, 2020

Published: February 19, 2020 
attractive for future studies, considering the pursuit of even higher laser powers and narrower spectral profiles will undoubtedly present a new series of challenges in the thermal management of alkali metal "runaway" processes. ${ }^{50-53}$

Because SEOP hyperpolarization utilizes gas-phase collisions between vaporized $\mathrm{Rb}$ and $\mathrm{Xe}$ atoms, elevated temperatures $\left(\sim 70{ }^{\circ} \mathrm{C}\right.$ for batch-mode, ${ }^{28,54} \sim 120{ }^{\circ} \mathrm{C}$ for continuous-flow configurations) are required to maintain sufficient $\mathrm{Rb}$ vapor densities for effective optical pumping. Continuous-flow hyperpolarizers, typically employing extremely dilute Xe gas mixtures, require a cryo-collection stage to remove buffering gases, ${ }^{32}$ allowing the HP Xe to be accumulated in the solid state, where the spin-lattice relaxation time $\left(T_{1}\right)$ is a few hours. ${ }^{55,56}$ Rapid thawing of the frozen Xe then takes place, before expansion into a temporary storage vessel, ${ }^{32}$ for example, Tedlar bag. By contrast, hyperpolarization in the batch-mode modality is typically performed using Xe-rich gas mixtures, and thus can be performed without the use of cryocollection, ${ }^{28,57}$ but still necessitates a "cool-down" stage where the reaction vessel (termed "SEOP cell") is reduced to $\sim 25-$ $50{ }^{\circ} \mathrm{C}$ before the gaseous HP contrast agent can be extracted, for example, for intended clinical use. ${ }^{54}$ The temperature reduction results in the $\mathrm{Rb}$ condensation in the SEOP cell and negligible (less than $5 \mathrm{ng}$ ) presence of $\mathrm{Rb}$ metal excipient in the Tedlar bag. ${ }^{54}$

Our previous batch-mode hyperpolarizer designs employ a forced air oven to heat and cool the SEOP cell, ${ }^{28,54,58,59}$ which is somewhat inefficient due to low thermal conductivity and heat capacity of air. For example, long times ( up to $24 \mathrm{~min}$ ) for heating up/cooling down the cell are therefore necessary in such a design, ${ }^{54}$ inherently limiting the rate and duty cycle of $\mathrm{HP}{ }^{129} \mathrm{Xe}$ production. Moreover, the useable ${ }^{129} \mathrm{Xe}$ net spin polarization decreases during the SEOP cell cooldown due to a period of spin-relaxation before eventual transfer of $\mathrm{HP}^{129} \mathrm{Xe}$ into the Tedlar bag. Here, we address these issues by incorporating a novel aluminum jacket design, whereby direct thermal contact with the SEOP cell ensures rapid transfer of heat during heating/cooling cycles. As a result, temperature ramping of the SEOP cell can be accomplished in $\sim 4 \mathrm{~min}$, that is, approximately 6 times faster than the previous designs. The results described in this study aim to both realize the efficiency and applicability of the new design for the purposes of increasing $\mathrm{HP}{ }^{129} \mathrm{Xe}$ contrast agent production rates for clinical use. Specifically, we demonstrate $\% P_{\mathrm{Xe}}$ of $54.8 \pm 3.8 \%$ at $\gamma_{\mathrm{SEOP}}$ of $0.035 \pm 0.004 \mathrm{~min}^{-1}$ and $\% P_{\mathrm{Xe}}$ of $\sim 40 \%$ at $\gamma_{\mathrm{SEOP}}$ of $\sim 0.1$ $\mathrm{min}^{-1}$ for 1000 Torr Xe mixture. $\% P_{\mathrm{Xe}}$ of $\sim 30 \%$ is achieved at $\gamma_{\text {SEOP }}$ of $\sim 0.06 \mathrm{~min}^{-1}$ for 1500 Torr Xe mixture. Moreover, high $\gamma_{\text {SEOP }}$ of $0.2 \mathrm{~min}^{-1}$ may enable new approaches for clinical-scale SEOP.

\section{MATERIALS AND METHODS}

In this study, ${ }^{129} \mathrm{Xe}$ hyperpolarization via SEOP was performed using an automated, third-generation (GEN-3) device, operating in the batch mode under conditions of high $\mathrm{Xe}$ partial pressures (i.e., Xe-rich mixtures) and high laser power $(\sim 170 \mathrm{~W})$. Optical pumping was performed using a BrightLock Ultra-500 continuous-wave pump laser source, with a 2" beam expanding telescope and a $1 / 4-\lambda$ waveplate providing circular polarization of purity $>98 \%$ (QPC Laser Technologies, Sylmar, CA). Frequency-narrowing was employed to achieve a spectral width of $0.154 \mathrm{~nm}$, with wavelength tuning onto the $\mathrm{Rb} \mathrm{D}_{1}$ transition wavelength facilitated by a thermistor and high-capacity P312 water chiller (Termotek, Baden-Baden,
Germany) operating at $930 \mathrm{~W}$ cooling power and a flow rate of $>4 \mathrm{~L} / \mathrm{min}$. The aluminum jacket design for heating and cooling of SEOP cells (Figure 1a and Figure 1d) consisted of four 50

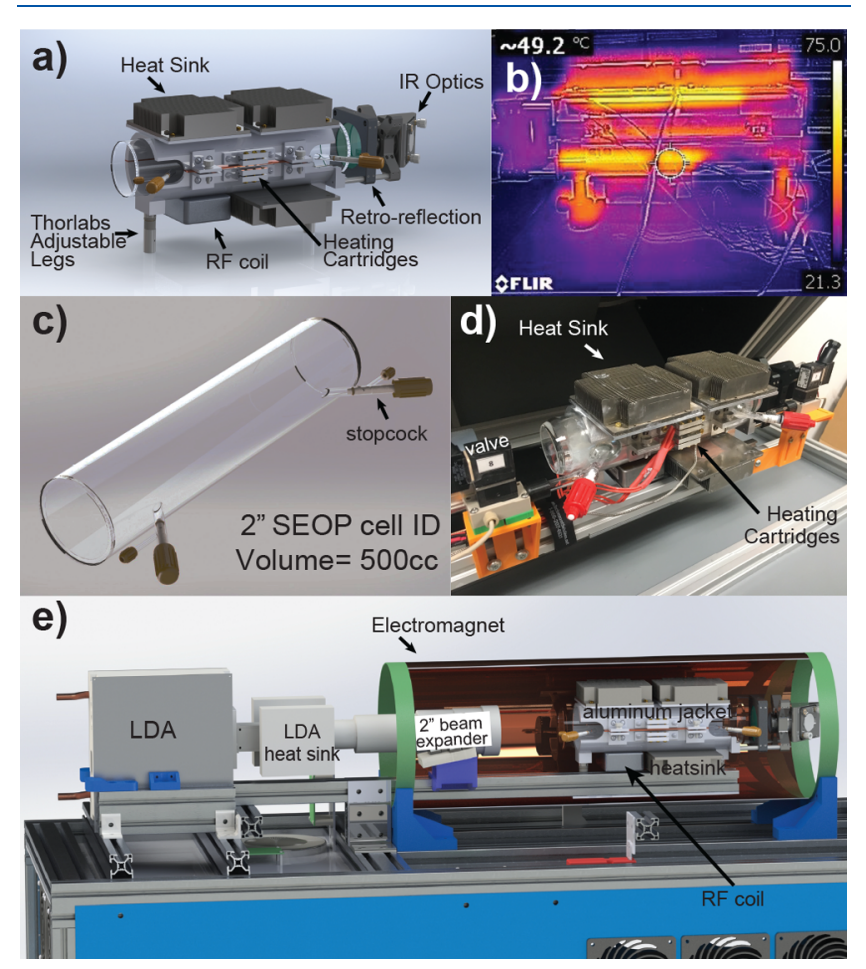

Figure 1. (a) 3D rendering of the aluminum heating jacket. (b) Thermal photo illustrating localized temperature of the heating elements, heat sinks and SEOP cell. (c) 3D rendering of the SEOP cell designed for the GEN-3 hyperpolarizer. (d) Photo showing aluminum heating jacket implementation on the GEN-3 hyperpolarizer. (e) 3D rendering of the GEN-3 hyperpolarizer upper chassis, illustrating the alignment of the pump laser, SEOP cell aluminum heating jacket, and NMR solenoid magnet coil (large horizontal cylinder shown as a cut-away to depict internal components).

W cartridge heaters in contact with a cylindrical aluminum frame. A series of three heat sinks were used to effectively dissipate heat during the cooling process, venting it to the main body of the GEN-3 hyperpolarizer chassis where it could be easily removed by a cluster of independently operated fans. A pair of ThorLabs adjustable pillars were utilized to perform pump laser alignment, with a retro-reflecting mirror situated at the rear of the SEOP cell increasing the optical pumping efficiency and allowing IR spectroscopy to be performed. A small rectangular opening was included at the bottom of the jacket structure to allow insertion of the NMR surface coil, for RF transmit pulses and receiving the NMR signal. A layer of Arctic Alumina thermal paste (thermal conductivity $>4 \mathrm{~W} /(\mathrm{m}$. $\mathrm{K})$ ) coated the interior surface of the jacket for rapid heat transfer (Figure 1b). The use of thermal paste adds a negligible additional time (ca. $10 \mathrm{~min}$ ) during the SEOP cell replacement process compared to previous designs. ${ }^{58-60}$ Although we do not have the metrics for how often the cell needs to be changed on this device yet, we are currently completing the quality assurance study for a previous-generation device (with similar geometry of the SEOP cell), ${ }^{58,60}$ and we find that the SEOP cell can be used for more than 500 refills or more than 1 year (whichever comes sooner), so the additional $10 \mathrm{~min}$ time 


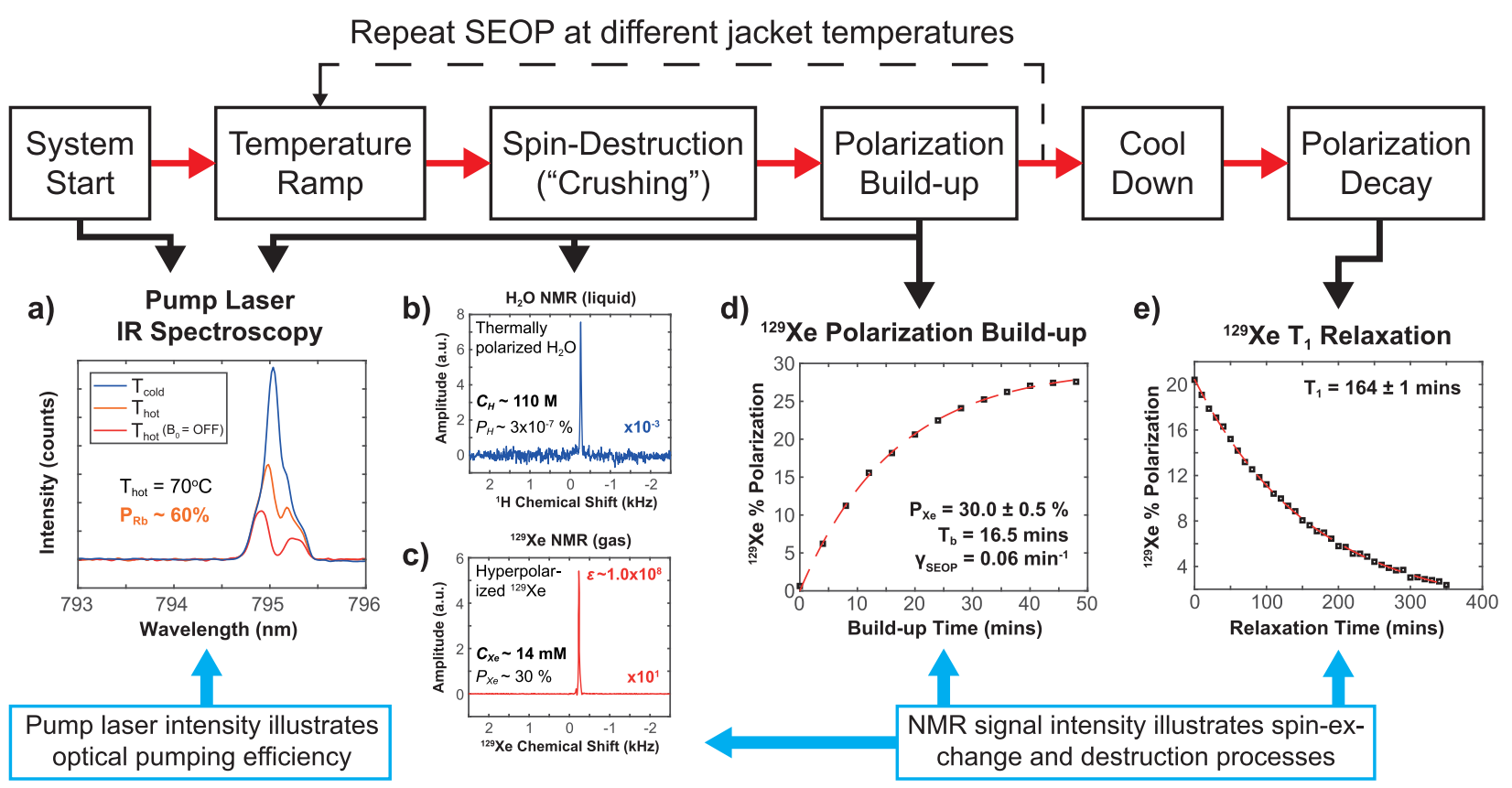

Figure 2. Flowchart describing the typical stages of operation of the GEN-3 hyperpolarizer device. Example data acquired during each stage of the SEOP process for the purposes of determining (a) Pump laser light absorption spectra employed for estimation of Rb electron polarization $\left(P_{\mathrm{Rb}}\right)$; (b) ${ }^{1} \mathrm{H}$ NMR spectroscopy of thermally polarized ${ }^{1} \mathrm{H}$ nuclei of a water phantom (doped with $10 \mathrm{mM} \mathrm{CuSO}_{4}$. of the same geometry shown in display (c); (c) ${ }^{129} \mathrm{Xe}$ NMR spectroscopy employed to measure nuclear spin polarization $\left(P_{\mathrm{Xe}}\right)$ relative to that of proton phantom; $(\mathrm{d}){ }^{129} \mathrm{Xe}$ polarization build-up curve employed to compute ${ }^{129} \mathrm{Xe}$ build-up rate $\left(\gamma_{\mathrm{SEOP}}\right)$ and steady-state $\% P_{\mathrm{Xe}}$; (e) ${ }^{129} \mathrm{Xe}$ polarization relaxation curve employed to compute the ${ }^{129} \mathrm{Xe} T_{1}$ decay rate- see SI Figure S1a for details.

required for application of thermal paste does not impact the process significantly.

The diameter of the SEOP cell (Figure 1c) matches size of the beam expander (2" o.d.). The SEOP cell has an internal volume of $0.5 \mathrm{~L}$ (Mid Rivers Glassblowing, Saint Peters, MO). The SEOP cell cleaning, preparation, and $\mathrm{Rb}$ loading processes are described in the Supporting Information (SI). A solenoid coil surrounded the SEOP cell and heating jacket, providing a homogeneous ( $\sim 300 \mathrm{ppm}$ over $5 \mathrm{~cm}$ sphere according to the design specifications) $B_{0}$ magnetic field of up to $40 \mathrm{G}(4 \mathrm{mT})$. The tuning of the RF coil was performed with it already inserted inside the aluminum case shown in Figure 1a, and the attachment to the aluminum jacket does not result in any observable RF coil detuning. The aluminum casing of the RF coil and the jacket provide excellent radio frequency (RF) screening of outside noise sources, resulting in improved NMR signal-to-noise ratio (SNR) compared to previous designs. ${ }^{53}$ $\mathrm{RF}$ pulse transmission and NMR detection were performed using a Kea2 NMR spectrometer (Magritek, New Zealand) at a $40.8 \mathrm{kHz} \mathrm{B}$ resonance frequency for both ${ }^{1} \mathrm{H}$ or ${ }^{129} \mathrm{Xe}$ spins. Since ${ }^{129} \mathrm{Xe}$ possesses a substantially lower gyromagnetic ratio $(-11.777 \mathrm{MHz} / \mathrm{T})$ relative to ${ }^{1} \mathrm{H}(42.576 \mathrm{MHz} / \mathrm{T})$, it was necessary to increase the $B_{0}$ field strength by the ratio of proton and ${ }^{129} \mathrm{Xe}$ gyromagnetic ratios (ca. factor of $\sim 3.6$ ) when acquiring ${ }^{129} \mathrm{Xe}$ to match these resonance frequencies at $40.8 \mathrm{kHz}$. Figure 1e shows 3D rendering of the hyperpolarizer upper chassis.

A Wi-Fi-enabled user interface allowed independently actuating solenoid valves and chassis fans, isolating various stages of the inlet, outlet, and vacuum lines and well as monitoring and tuning of laser power and wavelength, heating jacket temperature. Operation of the GEN-3 hyperpolarizer commenced with the enabling of the $B_{0}$ magnetic field (3.08 A), water chiller $\left(20.4^{\circ} \mathrm{C}\right)$, and LDA. To ensure repeatability,
IR spectroscopic measurements were performed on the pump laser at maximum current $(37 \mathrm{~A}, \sim 170 \mathrm{~W})$ before any SEOP cell heating took place (Figure $2 \mathrm{a}$ ). LDA power output was stable over different days of experimental operation, and it provided a baseline measurement of photon flux under conditions of zero optical pumping (owing to negligible $\mathrm{Rb}$ vapor density at low temperatures). Once stable on-resonance laser power was achieved, the Wi-Fi interface was used to perform programmed temperature ramping and achieve the desired jacket temperature. This resulted in vaporization of $\mathrm{Rb}$ and sufficient absorption of pump laser photons, enabling the SEOP process to commence. Calibration of RF pulses and computation of nuclear ${ }^{129} \mathrm{Xe}$ and electron $\mathrm{Rb}$ polarization levels is provided in the SI.

NMR and IR spectroscopic data were acquired at regular intervals throughout each experiment to determine SEOP parameters as functions of jacket temperature, build-up time, gas mixture composition, etc. After reaching steady-state polarization and data acquisition at a given temperature, the jacket temperature could be altered to repeat experiments at different temperatures, or the hyperpolarizer could be switched to a cool-down state, whereby all fans were enabled and pump laser power was reduced. Until sufficiently low cell temperatures were observed, the laser current was maintained just above the lasing threshold ( $\sim 10 \mathrm{~A})$ to minimize the effect of $\mathrm{Rb}$ vapor condensing on the front and rear windows of the SEOP cell.

After the cool-down stage had been completed, the gas mixture could either be expanded into a Tedlar bag for storage, transport, and/or clinical research use, or retained inside the SEOP cell for further experimentation. This time period was typically used to perform $T_{1}$ relaxation measurements, since ${ }^{129}$ Xe polarization could be maintained inside the solenoid coil $B_{0}$ field to a reasonably high level for several hours (Figure 2e). 


\section{RESULTS AND DISCUSSION}

Results from this study have been subdivided into two sections. The first of these pertains to the operational performance efficiency of the aluminum heating jacket for performing automated SEOP cell temperature ramping (Figure 3), and

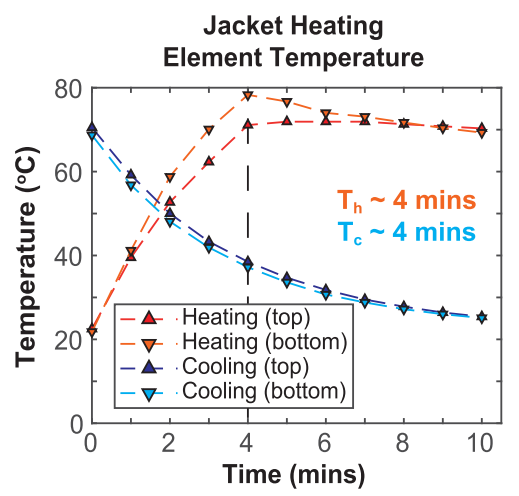

Figure 3. Temperature measurements of upper and lower jacket heating elements during a heating and cooling cycle between 22 and $70{ }^{\circ} \mathrm{C}$, with associated exponentially fitted heating $\left(T_{\mathrm{h}}\right)$ and cooling $\left(T_{\mathrm{c}}\right)$ times included.

illustrates the rapid time scales on which SEOP cell heating and cooling can be performed. Individual measurements of the upper and lower heating element temperatures were recorded over the span of $10 \mathrm{~min}$ during a heating and cooling cycle, along with exponential curve-fitted parameters of the respective temperature build-up and decay processes. This facilitated an estimation of the heating and cooling time constants $\left(T_{\mathrm{h}}\right.$ and $T_{\mathcal{c}}$, respectively). From room temperature $\left(\sim 22{ }^{\circ} \mathrm{C}\right)$, the jacket temperature was raised to a set-point of $70{ }^{\circ} \mathrm{C}$ using the Wi-Fi-enabled controller. After stabilization of temperature was achieved, the temperature set-point was returned to $20{ }^{\circ} \mathrm{C}$ and all fans were enabled. During temperature ramp-up, all four ( $50 \mathrm{~W}$ each) heating elements within the jacket reached the set-point of $70{ }^{\circ} \mathrm{C}$ in $<4 \mathrm{~min}$ $\left(T_{\mathrm{h}}\right)$. The slightly slower temperature build-up rate at the top heating element may be a result of its closer proximity to the cooling fans mounted on the top of the hyperpolarizer chassis, which naturally experienced greater airflow and more effective temperature dissipation. During the corresponding cooling cycle, both upper and lower parts of the jacket exhibited very similar temperature readings due to the significantly greater airflow throughout the chassis with all cooling fans enabled. A temperature of $\sim 38{ }^{\circ} \mathrm{C}$ (deemed as sufficient for release of HP ${ }^{129} \mathrm{Xe}$ gas mixture in the Tedlar bag in our previous studies ${ }^{54}$ ) was recorded on both heating elements after 4 min of cooling $(T c)$. This is an important threshold, because it is below the melting point of $\mathrm{Rb}\left(39.3{ }^{\circ} \mathrm{C}\right)$, ensuring that the $\mathrm{Rb}$ vapor density is sufficiently low to allow collection of HP ${ }^{129} \mathrm{Xe}$ contrast agent with very low (few nanograms) $\mathrm{Rb}$ content in the temporary storage container (e.g., Tedlar bag). ${ }^{54}$

Rapid heating and cooling in this way decreases the overall time required for the production rates of a batch of $\mathrm{HP}{ }^{129} \mathrm{Xe}$ (while increasing the duty cycle), as there is a reduced turnaround time between collecting one sample of HP contrast agent and commencing polarization within the next. The design presented here compares very favorably with our previous forced-air design, where the cool-down rate (for SEOP cell temperature reduction of $30{ }^{\circ} \mathrm{C}$ from 72 to $42{ }^{\circ} \mathrm{C}$ ) was $\sim 24 \min ^{54}$ - a factor of 6 overall improvement. Rapid and efficient cooling of the SEOP cell is also important in the clinical setting, as it results in a shorter period of spinrelaxation between reaching steady-state ${ }^{129} \mathrm{Xe}$ polarization and delivery of $\mathrm{HP}{ }^{129} \mathrm{Xe}$ contrast agent to subjects, allowing the ${ }^{129} \mathrm{Xe}$ to retain more polarization for the purposes of clinical imaging. For example, in our previous studies, $24 \mathrm{~min}$ long cool-down delay resulted in a $14.1 \pm 0.7 \%$ absolute polarization loss. $^{54}$

In addition to demonstration of rapid heating and cooling rates, we have performed the dynamic polarization build-up with the SEOP cell completely closed (Figure 4a) and SEOP

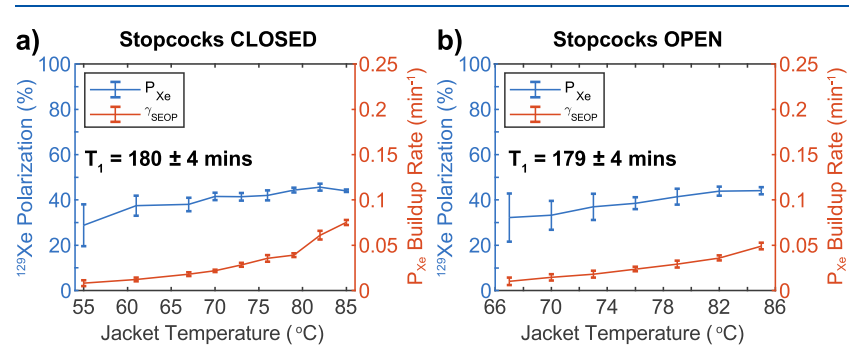

Figure 4. Steady-state $\% P_{\mathrm{Xe}}$ and $\gamma_{\mathrm{SEOP}}$ measurements during longlifetime (high $T_{1}$ ) SEOP in cells with identical 1000 Torr Xe/900 Torr $\mathrm{N}_{2} / 100$ Torr ${ }^{4} \mathrm{He}$ gas mixtures, with gas manifold stopcocks (a) closed and (b) open, as a function of the cell jacket temperature.

cell isolated from the rest of the gas loading manifold by a pair of nonmagnetic normally closed solenoid valves (Type 6126, Bürkert Fluid Control Systems, Huntersville, NC) (Figure 4b), mounted to a baseplate constructed from polyetheretherketone (PEEK). We note that the SEOP cell stopcocks (Figure 1) are not accessible while the hyperpolarizer upper chassis is sealed, and therefore the automatic SEOP cell refill can only be performed via opening of the solenoid valves. Figure 4 shows steady-state maximum $\% P_{\mathrm{Xe}}$ and $\gamma_{\mathrm{SEOP}}$ data (obtained using the method described in Figure 2d) from ${ }^{129}$ Xe polarization buildup as a function of temperature in the same SEOP cell, containing a 1000 Torr Xe/900 Torr $\mathrm{N}_{2} / 100$ Torr ${ }^{4} \mathrm{He}$ gas mixture; the only difference between the experiments is whether or not the manual stopcocks on the cell are open or closed. Importantly, the steady-state ${ }^{129} \mathrm{Xe}$ polarization, buildup rates, and ${ }^{129} \mathrm{Xe} T_{1}$ values are either nearly identical for the two experiments or follow similar trends, with the only major difference being a shift in the temperature value: for the experiments where the SEOP cell stopcocks were left open (Figure $4 \mathrm{~b}$ ), there is a noticeable decrease in both measurements at a given jacket temperature relative to that in Figure $4 \mathrm{a}$, where the stopcocks remained closed. This results in a temperature differential $\Delta T \approx 4{ }^{\circ} \mathrm{C}$ between the two regimes for comparable performance (e.g., steady-state $\% P_{\mathrm{Xe}} \approx 40 \%$, $\gamma_{\text {SEOP }} \approx 0.02 \mathrm{~min}^{-1}$ were observed after SEOP at jacket temperatures of $\sim 70$ and $75{ }^{\circ} \mathrm{C}$ when stopcocks were open and closed, respectively). Considering the long and nearly identical $T_{1}$ relaxation times $(\sim 3 \mathrm{~h})$, differing rates of spinrelaxation can be ruled out as a contributing factor to the observed difference in performance. There may be additional thermal coupling effects of the SEOP cell contents to the PEEK bases upon which the manifold gas-handling valves are mounted, resulting in greater heat dissipation and concomitant $\mathrm{Rb}$ vapor density reduction. Consequently, polarization buildup dynamics are slower as a result of reduced frequency of spin-exchanging collisions at the same nominal temperature. 
These effects require additional investigation to quantify their effect on SEOP.

Another important consideration for clinical-scale HP ${ }^{129} \mathrm{Xe}$ contrast agent production is repeatability. Here, we provide pilot results with our new PEEK-based gas-loading manifold. Sparse temperature maps of $\% P_{\mathrm{Xe}}$ and $\gamma_{\mathrm{SEOP}}$ recorded from two sequential in situ gas mixture refills (both 1000 Torr Xe/900 Torr $\mathrm{N}_{2} / 100$ Torr ${ }^{4} \mathrm{He}$ ) on the GEN-3 hyperpolarizer manifold in an identical SEOP cell are displayed in Figure 5.

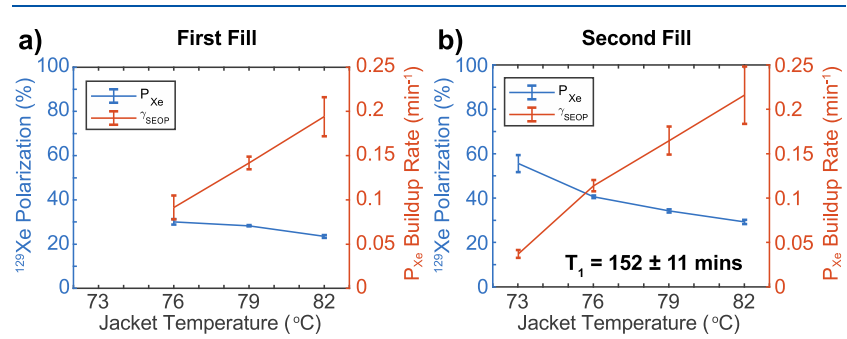

Figure 5. Pilot study on repeatability of steady-state $\% P_{\mathrm{Xe}}$ and $\gamma_{\mathrm{SEOP}}$ measurements in SEOP cells following long-lifetime (high $T_{1}$ ) SEOP in two separate refills of an identical 1000 Torr Xe/900 Torr $\mathrm{N}_{2} / 100$ Torr ${ }^{4} \mathrm{He}$ gas mixture as a function of optical cell jacket temperature. $T_{1}$ relaxation time was measured once only after temperature-mapping the second gas mixture load, shown in (b).

The results from the second gas mixture refill were actually better than those observed from the first, with an increase in $\%$ $P_{\mathrm{Xe}}$ most pronounced at lower jacket temperatures $\left(\% P_{\mathrm{Xe}}\right.$ value of $54.8 \pm 3.8 \%$ at $\gamma_{\text {SEOP }}$ of $0.035 \pm 0.004 \mathrm{~min}^{-1}$, Figure $5 \mathrm{~b}$ ), and a modest increase in $\gamma_{\text {SEOP }}$, which was more noticeable at higher jacket temperatures (the reason for omission of the results recorded at $73{ }^{\circ} \mathrm{C}$ in the first refill is that an especially low build-up rate led to a near-linear increase in $\% P_{\mathrm{Xe}}$ over the $60 \mathrm{~min}$ experimental duration, i.e., insufficient data). One explanation for the improved performance of the second fill is that heating and cooling multiple times sufficiently temperature-cycled the SEOP cell and yielded a more evenly distributed $\mathrm{Rb}$ spread across the interior walls (the stopcocks were closed during these experiments). This "curing" process would have given a higher $\mathrm{Rb}$ vapor density (as discussed previously regarding Figure 4) and a higher spin-exchange rate resulting in the improved ${ }^{129}$ Xe polarization levels and build-up rates. A $T_{1}$ relaxation measurement was performed immediately after acquiring results from the second fill and cooling the SEOP cell, yielding a long lifetime of $T_{1} \approx 2.5 \mathrm{~h}$. Since ${ }^{129} \mathrm{Xe}$ spin-relaxation processes are independent of the spin-exchange rate, the significance discrepancy in performance of the two SEOP runs is unlikely to be the result of some rapid change in $T_{1}$. Additionally, later SEOP cells that underwent additional heating and cooling cycles before being utilized in experiments did not experience this effect, so pre-SEOP "cell-curing" via temperature-cycling $(N>4)$ has become an important step in our methodology for improving reliability.

Figure 6a shows a selection of results from SEOP experiments performed on the GEN-3 hyperpolarizer under a variety of experimental conditions, including different gas mixtures and at different stages of SEOP cell life cycle. $\mathrm{Rb}$ polarization data is included where available. Figure 6a demonstrates that the maximum $\% P_{\mathrm{Xe}}$ values were consistently between $30 \%$ and $50 \%$ (in a wide range of temperatures ranging from 64 to $85{ }^{\circ} \mathrm{C}$ ) for the 1000 Torr Xe/900 Torr $\mathrm{N}_{2} /$ 100 Torr ${ }^{4} \mathrm{He}$ ternary gas mixture used in the majority of work a)

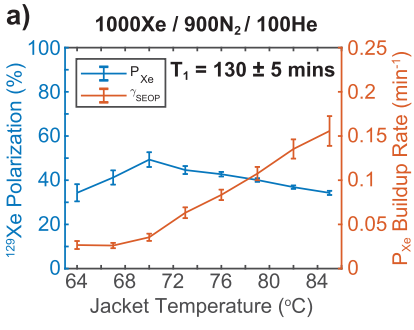

b)
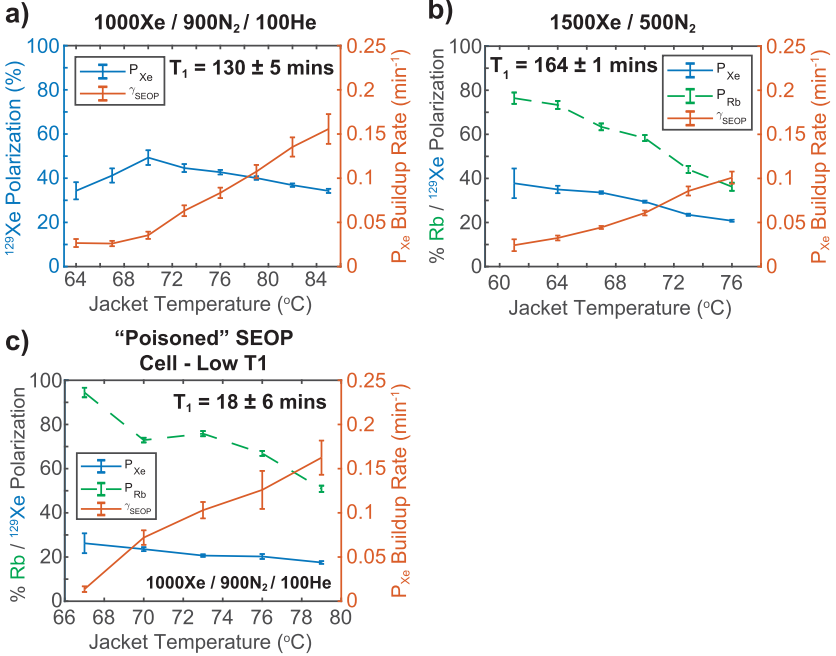

Figure 6. Temperature-dependent SEOP maps showing steady-state $\% P_{\text {Xe }}, \gamma_{\text {SEOP }}$ and (where available) $\% P_{\mathrm{Rb}}$ measurements following longlifetime (high $T_{1}$ ) SEOP in various experimental regimes as a function of jacket temperature. (a) 1000 Torr Xe/900 Torr $\mathrm{N}_{2} / 100$ Torr ${ }^{4} \mathrm{He}$ ternary gas mixture, (b) 1500 Torr Xe/500 Torr $\mathrm{N}_{2}$ binary gas mixture. Display (c) illustrates polarization build-up in a "poisoned" cell (i.e., where the $\mathrm{Rb}$ has been partially oxidized and where ${ }^{129} \mathrm{Xe} T_{1}$ is low) containing a 1000 Torr $\mathrm{Xe} / 900$ Torr $\mathrm{N}_{2} / 100$ Torr ${ }^{4} \mathrm{He}$ gas mixture.

for this study, peaking at $\% P_{\mathrm{Xe}} \sim 49.3 \pm 3.3 \%$ (at $\gamma_{\mathrm{SEOP}}$ of $\left.0.035 \pm 0.004 \mathrm{~min}^{-1}\right)$ for $70{ }^{\circ} \mathrm{C}$ build-up in the experiment described in Figure 6a.

A build-up rate exceeding $0.15 \mathrm{~min}^{-1}$ was observed at a maximum jacket temperature of $85{ }^{\circ} \mathrm{C}$, albeit under conditions far from $T_{\mathrm{OPT}}$ (corresponding to maximum $\% P_{\mathrm{Xe}}$ ) at $\sim 70{ }^{\circ} \mathrm{C}$, where $\gamma_{\text {SEOP }}$ was approximately 4.5 times slower. While these effects resulted in a reduction in $\% P_{\mathrm{Xe}}$ from $49.3 \pm 3.3 \%$ at 70 ${ }^{\circ} \mathrm{C}$ to $34.3 \pm 0.9 \%$ at $85{ }^{\circ} \mathrm{C}$ (i.e., approximately a factor of 1.30 decrease), it is very interesting to note that a significantly faster buildup of polarization in Xe-rich gas mixtures is still possible. We also note that Figure 5a showed an even faster $\gamma_{\text {SEOP }}$ value of $0.214 \pm 0.032 \mathrm{~min}^{-1}$ at these elevated jacket temperatures, clearly indicating that minor decreases in maximum $\% P_{\mathrm{Xe}}$ can be traded for significant gains in SEOP rates. For clinical-scale production, it may be beneficial to operate in these "hotter" conditions to facilitate more rapid hyperpolarization build-up and greater throughput of $\mathrm{HP}{ }^{129} \mathrm{Xe}$ contrast agent, at the expense of slightly reduced net magnetization and image contrast. Moreover, these ultrafast build-up rates in excess of $0.20 \mathrm{~min}^{-1}$ - corresponding to spin up times of only $\sim 5$ min.-compare favorably to the highest build-up rates achieved using the forced-air oven hyperpolarizer design. For example, 1000 Torr $\mathrm{Xe}$ and 1000 Torr $\mathrm{N}_{2}$ binary mixtures exhibited $\gamma_{\text {SEOP }}$ of $0.050 \pm 0.005 \mathrm{~min}^{-1}$ using similar laser power and SEOP cell dimensions ${ }^{53}$, a more than a factor of 4 increase in the build-up rate. We attribute these significant gains in $\gamma_{\text {SEOP }}$ to better thermal handling of the SEOP cell provided by the metal jacket. Furthermore, these fast build-up rates potentially pave the way to new modes of operation of high-pressure SEOP hyperpolarizers. ${ }^{61}$ For example, we envision an approach of employing automated temperature ramping (the concept described previously ${ }^{54}$ ) of the SEOP cell during polarization build-up process with faster build-up rates at the beginning of the cycle and slower build-up rates (corresponding to higher $\% P_{\mathrm{Xe}}$ ) at the end of the SEOP 
process. We also envision continuous-flow operation mode for this design at high Xe partial pressures, to mitigate the issue of cryo-collection and provide high production rates with acceptable $\% P_{\text {Xe }}$ levels.

We also compare three temperature maps of three SEOP cells presented in Figures $4 a, 5 b$, and $6 a$ filled with the same 1000 Torr $\mathrm{Xe} / 900$ Torr $\mathrm{N}_{2} / 100$ Torr ${ }^{4} \mathrm{He}$ gas mixture. All three SEOP cells performed similarly in terms of $\% P_{\mathrm{Xe}}$ as a function of $\gamma_{\text {SEOP }}$, in all three cases, $\% P_{\mathrm{Xe}}$ peaks $(45.6 \pm 1.5 \%$, $43.8 \pm 3.1 \%$, and $49.3 \pm 3.3 \%$, respectively) at $\gamma_{\text {SEOP }}$ of $0.03-$ $0.04 \mathrm{~min}^{-1}$. However, the significant variability of $\gamma_{\mathrm{SEOP}}$ as a function of temperature, which we attribute to variable $\mathrm{Rb}$ distribution during SEOP cell preparation. Since $T_{1}$ relaxation times were appreciably long in all cases (i.e., the spin destruction term (SI eq 5) $\Gamma_{\mathrm{Xe}}\left(1 / T_{1}\right)$ is significantly smaller compared to the build-up rates, we ignore $T_{1}$-limiting effects. Thus, we conclude that it is insufficient/nonuniform $\mathrm{Rb}$ distribution on the cell surfaces (affecting the $R b$ vapor density and spin-exchange rate) that leads to significant shifting in the temperature response, but no appreciable change in maximum $\% P_{\mathrm{Xe}}$.

Another desirable avenue for investigation for clinical-scale production of HP ${ }^{129} \mathrm{Xe}$ contrast agents is highly rich Xe gas mixtures. An increased Xe fraction results in a greater number of polarizable target nuclei, and thus a larger theoretical limit for magnetization and SNR if similar $\% P_{\mathrm{Xe}}$ values and spinexchange rates can be achieved. Figure $6 \mathrm{~b}$ displays results from a SEOP cell (with good ${ }^{129} \mathrm{Xe} \mathrm{T}_{1}>2.5 \mathrm{~h}$ ) using a 1500 Torr $\mathrm{Xe} / 500$ Torr $\mathrm{N}_{2}$ binary gas mixture. The maximum $\% P_{\mathrm{Xe}}$ is achieved at significantly lower temperatures than in the 1000 Torr Xe mixtures (e.g., Figure 6a), having already reached begun to decrease with temperature at $61{ }^{\circ} \mathrm{C}$ : $37.8 \pm 6.7 \%$ versus $49.3 \pm 3.3 \%$, respectively. This is not surprising, because similar trends have been observed using previous forced-air oven designs. ${ }^{53,62}$ We also note very similar trends in $\gamma_{\text {SEOP }}$ of the two mixtures shown in Figure $6 \mathrm{a}$ and $\mathrm{b}$. However, when taking into account the $50 \%$ increase in Xe fraction (Figure $6 \mathrm{~b}$ versus Figure 6a; resulting from the increased Xe-dependent $\mathrm{Rb}$ spin-destruction rate $\left.{ }^{63,64}\right)$, a decrease in $\% P_{\mathrm{Xe}}$ from $49.3 \pm$ $3.3 \%$ to $37.8 \pm 6.7 \%$, will generate $15 \%$ more magnetization, by virtue of the greater quantity of ${ }^{129} \mathrm{Xe}$ nuclei. From this perspective, the super-rich $75 \% \mathrm{Xe}$ mixture compares favorably at many of the jacket temperatures investigated during the study, only starting to suffer significant performance loss at high temperatures $\left(64-76{ }^{\circ} \mathrm{C}\right.$, Figure $6 \mathrm{~b}$ ) where the $\mathrm{Rb}$ polarization begins to markedly decrease, $\% P_{\mathrm{Rb}}$ fell to roughly $40 \%$ at a jacket temperature of $76{ }^{\circ} \mathrm{C}$ in the $75 \% \mathrm{Xe}$ gas mixture.

Figure $6 \mathrm{c}$ also shows a temperature map of the SEOP cell at the end its operational lifetime, that is, relatively short $T_{1}$ due to $\mathrm{Rb}$ "poisoning" (i.e., partial oxidation) by atmospheric oxygen or water vapor. Over the course of multiple gas mixture refills and accidental SEOP cell exposure, oxidizing impurities such as $\mathrm{O}_{2}$ and $\mathrm{H}_{2} \mathrm{O}$ may accumulate inside the SEOP cell, reacting to form $\mathrm{Rb}$ oxides. This condition serves to not only suppress the $\mathrm{Rb}$ vapor density, but also contributes actively to spin-destruction rate $\left(1 / T_{1}\right)$ from Xe-wall collisions. The maximum ${ }^{129} \mathrm{Xe}$ polarization observed from the SEOP cell employed in this experiment was substantially lower $(26.2 \pm$ $4.5 \%$ at $T_{\mathrm{OPT}}=67{ }^{\circ} \mathrm{C}$ and a build-up rate $\gamma_{\mathrm{SEOP}}=0.014 \pm$ $0.003 \mathrm{~min}^{-1}$ ) and steadily decreased with increasing jacket temperature. The observation that high levels of ${ }^{129} \mathrm{Xe}$ polarization cannot be recovered by simply increasing the temperature further to achieve an equivalent $\mathrm{Rb}$ vapor density (besides decreased $\% P_{\mathrm{Rb}}$ at elevated $\mathrm{Rb}$ gas-phase densities) is likely due to increased spin-relaxation effects due to the presence of paramagnetic impurities. Further evidence for this effect can be obtained from the build-up rate in this cell, $\gamma_{\mathrm{SEO}}$, which rapidly increases even as $\% P_{\mathrm{Xe}}$ remains low. While such a short relaxation time would traditionally render such "poisoned" SEOP cells useless to clinical-scale HP ${ }^{129} \mathrm{Xe}$ contrast agent production (because lengthy (e.g., 24 minlong ${ }^{54}$ ) cool-down process renders significant ${ }^{129} \mathrm{Xe}$ polarization loss), the rapid cooling potential of the GEN-3 hyperpolarizer aluminum jacket (ca. 4 min) means that useful magnetization can still be observed even after cooling the SEOP cell before HP ${ }^{129} \mathrm{Xe}$ gas mixture ejection. The fast build-up rates and fast temperature cycling may potentially allow the completion of polarization cycles in as little as 25 min, which may be desirable in clinical settings $(8 \mathrm{~min}$ for temperature manipulation and ejection and $17 \mathrm{~min}$ of polarization build-up $\left(\gamma_{\text {SEOP }} \rightarrow 0.2 \mathrm{~min}^{-1}\right)$, resulting in a production rate of $1.9 \mathrm{~L} /$ hour of $\sim 25 \%$-hyperpolarized (estimated) Xe: $\mathrm{N}_{2}$ (50:50) mixture, corresponding to the dose equivalent $\left(\mathrm{DE}^{65}\right)$ of $\sim 0.24 \mathrm{~L}$ of $100 \%$ hyperpolarized $100 \%$ enriched pure ${ }^{129} \mathrm{Xe}$ gas (assuming that $100 \%$ enriched ${ }^{129} \mathrm{Xe}$ is employed).

Lastly, we note that the presented data indicates a greaterthan-expected difference between $\% P_{\mathrm{Xe}}$ and $\% P_{\mathrm{Rb}}$ recorded measurements (roughly a factor of 1.8 when considering Figure $6 \mathrm{~b}$ and $\mathrm{c}$ ), which previous studies have suggested should not typically exceed a factor of 1.3 in equally dense binary $\mathrm{Xe} / \mathrm{N}_{2}$ gas mixtures under conditions of similar polarization build-up rates, for example, $\gamma_{\mathrm{SEOP}}>0.1 \mathrm{~min}^{-1}$ at $73{ }^{\circ} \mathrm{C}$ (Figure 6c) and similar (long) ${ }^{129} \mathrm{Xe}$ relaxation times. ${ }^{53}$ More generally, the steady-state xenon polarization should in principle approach that of the $\mathrm{Rb}$, once multiplied by the ratio of the spin-exchange rate to the SEOP build-up rate (i.e., $\% P_{\mathrm{Xe}}$ $\left.=\% P_{\mathrm{Rb}} \cdot\left(\gamma_{\mathrm{SE}} / \gamma_{\mathrm{SEOP}}\right)\right) .^{53,58} \mathrm{We}$ believe the present deviation from this expectation is a consequence of the GEN-3 hyperpolarizer design: Specifically, we note that the ends (approximately 1" in the front and 1" in the back) of the SEOP cell are not covered by the aluminum jacket (Figure 1a), because the very ends of the SEOP cell have $\sim^{1 /}$ " greater diameter as a result of the fusion (i.e., glass welding) process of the optical windows and 2 " glass tubing. Figure $2 \mathrm{~b}$ shows that the ends of the SEOP cell (not covered by the jacket) may indeed be significantly colder than the rest of the SEOP cell due to contact with ambient air. We speculate that these colder regions of the cell do not constructively contribute to the SEOP process because of very low local density of $\mathrm{Rb}$ vapor atoms-leading to negligible regional build-up rates, even though $\mathrm{Rb}$ polarization appears to be high as estimated from the average $\% P_{\mathrm{Rb}}$ along the length of the OP cell-as a consequence of having these cold and therefore "inert" regions, the gas convection may effectively average out ${ }^{129} \mathrm{Xe}$ polarization and would lead to apparent lowering of ${ }^{129} \mathrm{Xe}$ polarization values. Our future studies are aimed at improving this aspect of the aluminum jacket while maintaining the key benefits of this new design.

\section{CONCLUSIONS}

This work demonstrates the use of the cartridge-heated aluminum jacket design for rapid SEOP cell heating and cooling, with heating and cooling times reduced several-fold, down to $\sim 4 \mathrm{~min}$, and improved thermal stability of the 
polarization process. The reduced preparation time during heating (to ensure sufficiently dense $\mathrm{Rb}$ vapor) and cool-down time (to minimize $T_{1}$ spin-relaxation losses) of this design has the potential to significantly scale-up production rates of $\mathrm{HP}$ ${ }^{129} \mathrm{Xe}$ contrast agent clinical-scale production compared to the previous forced-air designs. ${ }^{45,53,54,58,59}$ The preliminary quality assurance studies performed on the GEN-3 ${ }^{129} \mathrm{Xe}$ hyperpolarizer indicate high levels of polarization are achievable in Xe-rich gas mixtures on clinically relevant time scales and quantities: for example, $\% P_{\mathrm{Xe}}$ value of $54.8 \pm 3.8 \%$ at $\gamma_{\mathrm{SEOP}}$ of $0.035 \pm 0.004 \mathrm{~min}^{-1}$ at 1000 Torr Xe pressure. Moreover, high $\sim 40 \% P_{\mathrm{Xe}}$ is maintained at $\sim 0.1 \mathrm{~min}^{-1} \gamma_{\mathrm{SEOP}}$ for 1000 Torr Xe mixture, and $\sim 30 \% P_{\mathrm{Xe}}$ is maintained at $0.06 \mathrm{~min}^{-1} \gamma_{\mathrm{SEOP}}$ for 1500 Torr $\mathrm{Xe}$ mixture. The initial results show good repeatability. Furthermore, production rates with $\gamma_{\text {SEOP }}$ as high as $0.2 \mathrm{~min}^{-1}$ have been demonstrated, which may enable more efficient approaches for clinical-scale SEOP at high $\mathrm{Xe}$ densities.

\section{ASSOCIATED CONTENT}

\section{SI Supporting Information}

The Supporting Information is available free of charge at https://pubs.acs.org/doi/10.1021/acs.analchem.9b05051.

Methodologies for cleaning, preparation, and loading of SEOP cells for use on the GEN-3 hyperpolarizer device; procedures for performing NMR/IR data analysis using MATLAB and associated MATLAB code; comparison of MATLAB data processing with previous manual calculation methods to demonstrate integrity and reliability of presented results and conclusions (PDF)

\section{AUTHOR INFORMATION}

\section{Corresponding Authors}

Eduard Y. Chekmenev - Department of Chemistry, Integrative Biosciences (Ibio), Wayne State University, Karmanos Cancer Institute (KCI), Detroit, Michigan 48202, United States; Russian Academy of Sciences, Moscow 119991, Russia; 다이.org/0000-0002-8745-8801; Email: chekmenev@ wayne.edu

Panayiotis Nikolaou - XeUS Technologies LTD, Nicosia 2312, Cyprus; Email: peternikolaou78@gmail.com

\section{Authors}

Jonathan R. Birchall - Department of Chemistry, Integrative Biosciences (Ibio), Wayne State University, Karmanos Cancer Institute (KCI), Detroit, Michigan 48202, United States

Aaron M. Coffey - Department of Radiology, Vanderbilt University Institute of Imaging Science (VUIIS), Nashville, Tennessee 37232, United States

Bryce E. Kidd - Department of Chemistry and Biochemistry, Southern Illinois University, Carbondale, Illinois 62901, United States

Megan Murphy - Department of Chemistry and Biochemistry, Southern Illinois University, Carbondale, Illinois 62901, United States

Michael Molway - Department of Chemistry and Biochemistry, Southern Illinois University, Carbondale, Illinois 62901, United States

Liana B. Bales - Department of Chemistry and Biochemistry, Southern Illinois University, Carbondale, Illinois 62901, United States
Boyd M. Goodson - Department of Chemistry and Biochemistry and Materials Technology Center, Southern Illinois University, Carbondale, Illinois 62901, United States; (1) orcid.org/0000-0001-6079-5077

Robert K. Irwin - Sir Peter Mansfield Imaging Centre, University of Nottingham, Nottingham NG7 2RD, United Kingdom

Michael J. Barlow - Sir Peter Mansfield Imaging Centre, University of Nottingham, Nottingham NG7 2RD, United Kingdom

Complete contact information is available at:

https://pubs.acs.org/10.1021/acs.analchem.9b05051

\section{Notes}

The authors declare the following competing financial interest(s): P.N., B.M.G., and E.Y.C. declare the stake of ownership in XeUS Technologies, Ltd.

\section{ACKNOWLEDGMENTS}

This work was supported by DOD CDMRP W81XWH-12-10159/BC112431, W81XWH-15-1-0271, W81XWH-15-10272 .

\section{REFERENCES}

(1) Raftery, D.; Reven, L.; Long, H.; Pines, A.; Tang, P.; Reimer, J. A. J. Phys. Chem. 1993, 97 (8), 7.

(2) Spence, M. M.; Rubin, S. M.; Dimitrov, I. E.; Ruiz, E. J.; Wemmer, D. E.; Pines, A.; Yao, S. Q.; Tian, F.; Schultz, P. G. Proc. Natl. Acad. Sci. U. S. A. 2001, 98 (19), 10654-10657.

(3) Nossov, A.; Haddad, E.; Guenneau, F.; Mignon, C.; Gedeon, A.; Grosso, D.; Babonneau, F.; Bonhomme, C.; Sanchez, C. Chem. Commun. 2002, No. 21, 2476-2477.

(4) Pavlovskaya, G. E.; Cleveland, Z. I.; Stupic, K. F.; Basaraba, R. J.; Meersmann, T. Proc. Natl. Acad. Sci. U. S. A. 2005, 102, 1827518279.

(5) Schroder, L.; Lowery, T. J.; Hilty, C.; Wemmer, D. E.; Pines, A. Science 2006, 314 (5798), 446-449.

(6) Berthault, P.; Huber, G.; Desvaux, H. Prog. Nucl. Magn. Reson. Spectrosc. 2009, 55, 35-60.

(7) Boutin, C.; Stopin, A.; Lenda, F.; Brotin, T.; Dutasta, J.; Jamin, N.; Sanson, A.; Boulard, Y.; Leteurtre, F.; Huber, G.; BogaertBuchmann, A.; Tassali, N.; Desvaux, H.; Carrière, M.; Berthault, P. Bioorg. Med. Chem. 2011, 19 (13), 9.

(8) Albert, M. S.; Cates, G. D.; Driehuys, B.; Happer, W.; Saam, B.; Springer, C. S.; Wishnia, A. Nature 1994, 370 (6486), 199-201.

(9) Salerno, M.; de Lange, E. E.; Altes, T. A.; Truwit, J. D.; Brookeman, J. R.; Mugler, J. P. Radiology 2002, 222, 252-260.

(10) Wild, J. M.; Teh, K.; Woodhouse, N.; Paley, M. N. J.; Fichele, S.; de Zanche, N.; Kasuboski, L. J. Magn. Reson. 2006, 183 (1), 1324.

(11) Patz, S.; Muradian, I.; Hrovat, M. I.; Ruset, I. C.; Topulos, G.; Covrig, S. D.; Frederick, E.; Hatabu, H.; Hersman, F. W.; Butler, J. P. Acad. Radiol. 2008, 15 (6), 713-727.

(12) Kaushik, S. S.; Cleveland, Z. I.; Cofer, G. P.; Metz, G.; Beaver, D.; Nouls, J.; Kraft, M.; Auffermann, W.; Wolber, J.; McAdams, H. P.; Driehuys, B. Magn. Reson. Med. 2011, 65 (4), 1155-1165.

(13) Driehuys, B.; Martinez-Jimenez, S.; Cleveland, Z. I.; Metz, G. M.; Beaver, D. M.; Nouls, J. C.; Kaushik, S. S.; Firszt, R.; Willis, C.; Kelly, K. T.; Wolber, J.; Kraft, M.; McAdams, H. P. Radiology 2012, 262, 279-289.

(14) Muradyan, I.; Butler, J. P.; Dabaghyan, M.; Hrovat, M.; Dregely, I.; Ruset, I.; Topulos, G. P.; Frederick, E.; Hatabu, H.; Hersman, W. F.; Patz, S. J. Magn. Reson. Imaging 2013, 37 (2), 457470.

(15) Walkup, L. L.; Woods, J. C. NMR Biomed. 2014, 27 (12), $1429-1438$. 
(16) Mazzanti, M. L.; Walvick, R. P.; Zhou, X.; Sun, Y. P.; Shah, N.; Mansour, J.; Gereige, J.; Albert, M. S. PLoS One 2011, 6 (7), 7.

(17) Mugler, J. P.; Altes, T. A. J. Magn. Reson. Imaging 2013, 37 (2), 313-331.

(18) Goodson, B. M. J. Magn. Reson. 2002, 155 (2), 157-216.

(19) Branca, R. T.; Cleveland, Z. I.; Fubara, B.; Kumar, C. S. S. R.; Maronpot, R. R.; Leuschner, C.; Warren, W. S.; Driehuys, B. Proc. Natl. Acad. Sci. U. S. A. 2010, 107 (8), 3693-3697.

(20) Branca, R. T.; He, T.; Zhang, L.; Floyd, C. S.; Freeman, M.; White, C.; Burant, A. Proc. Natl. Acad. Sci. U. S. A. 2014, 111 (50), 18001-18006.

(21) Schroder, L. Phys. Medica 2013, 29 (1), 3-16.

(22) Witte, C.; Schroder, L. NMR Biomed. 2013, 26 (7), 788-802.

(23) Barskiy, D. A.; Coffey, A. M.; Nikolaou, P.; Mikhaylov, D. M.; Goodson, B. M.; Branca, R. T.; Lu, G. J.; Shapiro, M. G.; Telkki, V.V.; Zhivonitko, V. V.; Koptyug, I. V.; Salnikov, O. G.; Kovtunov, K. V.; Bukhtiyarov, V. I.; Rosen, M. S.; Barlow, M. J.; Safavi, S.; Hall, I. P.; Schröder, L.; Chekmenev, E. Y. Chem. - Eur. J. 2017, 23 (4), 725751.

(24) Antonacci, M. A.; McHugh, C.; Kelley, M.; McCallister, A.; Degan, S.; Branca, R. T. Sci. Rep. 2019, 9 (1), 14865.

(25) Patz, S.; Hersman, F. W.; Muradian, I.; Hrovat, M. I.; Ruset, I. C.; Ketel, S.; Jacobson, F.; Topulos, G. P.; Hatabu, H.; Butler, J. P. Eur. J. Radiol. 2007, 64 (3), 335-344.

(26) Nikolaou, P.; Goodson, B. M.; Chekmenev, E. Y. Chem. - Eur. J. 2015, 21 (8), 3156-3166.

(27) Goodson, B. M.; Whiting, N.; Coffey, A. M.; Nikolaou, P.; Shi, F.; Gust, B.; Gemeinhardt, M. E.; Shchepin, R. V.; Skinner, J. G.; Birchall, J. R.; Barlow, M. J.; Chekmenev, E. Y., Hyperpolarization Methods for MRS. In eMagRes: Handbook of in vivo Magnetic Resonance Spectroscopy; Griffiths, J.; Bottomley, P.; Wasylishen, R. E., Eds.; John Wiley \& Sons, Ltd: West Sussex, UK, 2015; Vol. 4, pp 797-810.

(28) Nikolaou, P.; Coffey, A. M.; Walkup, L. L.; Gust, B. M.; Whiting, N.; Newton, H.; Barcus, S.; Muradyan, I.; Dabaghyan, M.; Moroz, G. D.; Rosen, M.; Patz, S.; Barlow, M. J.; Chekmenev, E. Y.; Goodson, B. M. Proc. Natl. Acad. Sci. U. S. A. 2013, 110, 1415014155.

(29) Walker, T. G.; Happer, W. Rev. Mod. Phys. 1997, 69 (2), 629642.

(30) Walker, T. G. J. Phys. Conf. Ser. 2011, 294, 012001.

(31) Bhaskar, N. D.; Happer, W.; McClelland, T. Phys. Rev. Lett. 1982, 49 (1), 25-28.

(32) Driehuys, B.; Cates, G. D.; Miron, E.; Sauer, K.; Walter, D. K.; Happer, W. Appl. Phys. Lett. 1996, 69 (12), 1668-1670.

(33) Zook, A. L.; Adhyaru, B. B.; Bowers, C. R. J. Magn. Reson. 2002, 159 (2), 175-182.

(34) Ruset, I. C.; Ketel, S.; Hersman, F. W. Phys. Rev. Lett. 2006, 96 (5), 053002.

(35) Schrank, G.; Ma, Z.; Schoeck, A.; Saam, B. Phys. Rev. A: At., Mol., Opt. Phys. 2009, 80 (6), 063424.

(36) Hersman, F. W.; Ruset, I. C.; Ketel, S.; Muradian, I.; Covrig, S. D.; Distelbrink, J.; Porter, W.; Watt, D.; Ketel, J.; Brackett, J.; Hope, A.; Patz, S. Acad. Radiol. 2008, 15 (6), 10.

(37) Norquay, G.; Collier, G. J.; Rao, M.; Stewart, N. J.; Wild, J. M. Phys. Rev. Lett. 2018, 121 (15), 153201.

(38) Rosen, M. S.; Chupp, T. E.; Coulter, K. P.; Welsh, R. C.; Swanson, S. D. Rev. Sci. Instrum. 1999, 70 (2), 1546-1552.

(39) Saha, I.; Nikolaou, P.; Whiting, N.; Goodson, B. M. Chem. Phys. Lett. 2006, 428 (4-6), 268-276.

(40) Baranga, A. B.-A.; Appelt, S.; Erickson, C. J.; Young, A. R.; Happer, W. Phys. Rev. A: At., Mol., Opt. Phys. 1998, 58, 2282.

(41) Fink, A.; Brunner, E. Appl. Phys. B: Lasers Opt. 2007, 89 (1), 7.

(42) Ottinger, C.; Scheps, R.; York, G. W.; Gallagher, A. Phys. Rev. A: At., Mol., Opt. Phys. 1975, 11 (6), 14.

(43) Romalis, M. V.; Miron, E.; Cates, G. D. Phys. Rev. A: At., Mol., Opt. Phys. 1997, 56 (6), 4569-4578.

(44) Couture, A. H.; Clegg, T. B.; Driehuys, B. J. Appl. Phys. 2008, 104 (9), 6.
(45) Nikolaou, P.; Whiting, N.; Eschmann, N. A.; Chaffee, K. E.; Goodson, B. M. J. Magn. Reson. 2009, 197 (2), 249-254.

(46) Chann, B.; Nelson, I.; Walker, T. G. Opt. Lett. 2000, 25 (18), $1352-1354$.

(47) Zhu, H.; Ruset, I. C.; Hersman, F. W. Opt. Lett. 2005, 30 (11), $1342-1344$.

(48) Babcock, E.; Chann, B.; Nelson, I. A.; Walker, T. G. Appl. Opt. 2005, 44, 3098-3104.

(49) Zerger, J. N.; Lim, M. J.; Coulter, K. P.; Chupp, T. E. Appl. Phys. Lett. 2000, 76 (14), 1798-1800.

(50) Witte, C.; Kunth, M.; Rossella, F.; Schröder, L. J. Chem. Phys. 2014, 140 (8), 084203.

(51) Freeman, M. S.; Emami, K.; Driehuys, B. Phys. Rev. A: At., Mol., Opt. Phys. 2014, 90 (2), 023406.

(52) Antonacci, M. A.; Burant, A.; Wagner, W.; Branca, R. T. J. Magn. Reson. 2017, 279, 8.

(53) Nikolaou, P.; Coffey, A. M.; Ranta, K.; Walkup, L. L.; Gust, B.; Barlow, M. J.; Rosen, M. S.; Goodson, B. M.; Chekmenev, E. Y. J. Phys. Chem. B 2014, 118 (18), 4809-4816.

(54) Nikolaou, P.; Coffey, A. M.; Barlow, M. J.; Rosen, M.; Goodson, B. M.; Chekmenev, E. Y. Anal. Chem. 2014, 86 (16), 82068212.

(55) Cates, G. D.; Benton, D. R.; Gatzke, M.; Happer, W.; Hasson, K. C.; Newbury, N. R. Phys. Rev. Lett. 1990, 65, 2591-2594.

(56) Gatzke, M.; Cates, G. D.; Driehuys, B.; Fox, D.; Happer, W.; Saam, B. Phys. Rev. Lett. 1993, 70 (5), 690-693.

(57) Six, J. S.; Hughes-Riley, T.; Stupic, K. F.; Pavlovskaya, G. E.; Meersmann, T. PLoS One 2012, 7 (11), 16.

(58) Nikolaou, P.; Coffey, A. M.; Walkup, L. L.; Gust, B.; LaPierre, C.; Koehnemann, E.; Barlow, M. J.; Rosen, M. S.; Goodson, B. M.; Chekmenev, E. Y. J. Am. Chem. Soc. 2014, 136 (4), 1636-1642.

(59) Nikolaou, P.; Coffey, A. M.; Walkup, L. L.; Gust, B. M.; Whiting, N. R.; Newton, H.; Muradyan, I.; Dabaghyan, M.; Ranta, K.; Moroz, G.; Patz, S.; Rosen, M. S.; Barlow, M. J.; Chekmenev, E. Y.; Goodson, B. M. Magn. Reson. Imaging 2014, 32 (5), 541-550.

(60) Skinner, J. G.; Ranta, K.; Whiting, N.; Coffey, A. M.; Nikolaou, P.; Rosen, M. S.; Chekmenev, E. Y.; Morris, P. G.; Barlow, M. J.; Goodson, B. M. J. Magn. Reson. 2020, 312, 106686.

(61) Mortuza, M. G.; Anala, S.; Pavlovskaya, G. E.; Dieken, T. J.; Meersmann, T. J. Chem. Phys. 2003, 181, 1581.

(62) Whiting, N.; Nikolaou, P.; Eschmann, N. A.; Barlow, M. J.; Goodson, B. M. J. Magn. Reson. 2011, 208 (2), 298-304.

(63) Bouchiat, M. A.; Brossel, J.; Pottier, L. C. J. Chem. Phys. 1972, 56, 3703-3714.

(64) Nelson, I. A.; Walker, T. G. Phys. Rev. A: At., Mol., Opt. Phys. 2001, 65, 012712.

(65) He, M.; Robertson, S. H.; Kaushik, S. S.; Freeman, M. S.; Virgincar, R. S.; Davies, J.; Stiles, J.; Foster, W. M.; McAdams, H. P.; Driehuys, B. Magn. Reson. Imaging 2015, 33 (7), 877-885. 